\title{
Giant Neck Mass in a Patient with Mallampati Classification 3- Anaesthetic Management
}

\author{
Sheetal Madavi ${ }^{1}$, Jayashree Sen ${ }^{2}$ \\ ${ }^{1}$ Department of Anaesthesia, Acharya Vinoba Bhave Rural Hospital, Datta Meghe Institute of Medical \\ Sciences, Wardha, Maharashtra, India. ${ }^{2}$ Department of Anaesthesia, Acharya Vinoba Bhave Rural \\ Hospital, Datta Meghe Institute of Medical Sciences, Wardha, Maharashtra, India.
}

\section{INTRODUCTION}

The American Society of Anesthesiologists (ASA) task force defined a difficult airway as "a clinical situation in which a conventionally trained anaesthesiologist experiences difficulty with mask ventilation, difficulty with tracheal intubation, or both".[1] The task force further noted that the "difficult airway" represented a complex interaction between patient factors, the clinical setting, and the skills and preferences of the practitioner. Lipomas are slow-growing benign soft-tissue tumours which are typically asymptomatic. Giant lipomas in the cervical region of neck are rare. A lipoma is considered to be of excessive size when it exceeds $10 \mathrm{~cm}$ in length in any dimension or weighs over $1000 \mathrm{~g}$. During induction of anaesthesia, a huge mass on the back of neck which does not allow the patient to lie supine is a risk factor for difficult airway.[2,3,4]

Proper positioning is pertinent for induction of anaesthesia, securing the airway and surgical accessibility. In patients with anticipated difficult airway, fiberoptic intubation under spontaneous ventilation has been considered an effective and safe choice, taking into account that laryngoscopic intubation may worsen any difficult airway scenario.[5] We report a case of huge lipoma over the back of neck that limits neck movements in a patient having mouth opening of one finger due to chronic tobacco chewing.

A mass on upper back which limits positioning of the patient supine for induction of anaesthesia is a challenge for anaesthesiologists for the management of airway. Complications due to airway manipulation are one of the commonest causes for anaesthesia related morbidities and mortalities. We report the anaesthetic management of a 55 year old male patient, having mouth opening of one finger due to chronic tobacco chewing, protruding teeth in upper jaw and missing teeth in lower jaw scheduled for resection of a giant mass (huge lipoma), over the upper back that restricted flexion and extension movement of the neck. We selected awake fibreoptic bronchoscopy assisted endotracheal intubation as a safe approach in this difficult airway scenario.

\author{
Corresponding Author \\ Dr. Jayashree Sen, \\ House No. 4, Flat No. 7, \\ Meghdoot Apartment, \\ Sawangi, wardha, \\ Maharashtra, India. \\ E-mail: jayashree_sen@rediffmail.com
}

DOI: $10.14260 /$ jemds/2020/452

How to Cite This Article:

Madavi S, Sen J. Giant neck mass in a patient with mallampati classification 3anaesthetic management. J. Evolution Med. Dent. Sci. 2020;9(29):2074-2077, DOI: $10.14260 /$ jemds $/ 2020 / 452$

Submission 19-04-2020,

Peer Review 12-06-2020,

Acceptance 19-06-2020,

Published 20-07-2020.

Copyright (C) 2020 JEMDS. This is an open access article distributed under Creative Commons Attribution License [Attribution 4.0 International (CC BY 4.0)] 


\section{PRESENTATION OF CASE}

A 55-year-old male patient came to our medical college hospital about 4 months back (Dec. 2019), with a mobile, smooth-surfaced painless giant mass over back of the neck extending towards shoulders and upper back of 12 years duration. Size of the mass had increased recently; it had started to restrict the patient's neck movements and was causing distress by the resulting cosmetic deformity. The huge lipoma prevented him from lying in supine position, caused difficulty while sitting or getting dressed up in erect position and caused him embarrassment while facing people. The patient had no relevant family history, systemic comorbidity or any specific predisposing factor. He was a chronic tobacco chewer for about 25 yrs. His mouth opening was reduced and had protruding upper teeth and missing lower teeth. Local examination revealed an $18 \times 12 \mathrm{cms}$ sized ovoid, soft, smooth surfaced, mobile, non-tender, non-pulsatile, mass with no bruit (fig. 1 and 2). A fine needle aspiration cytology showed fibrofatty tissue histopathologically. A well-circumscribed ovoid homogeneous mass was detected at contrast enhanced computerized tomography. Elective surgery was planned.

\section{Preoperative Challenges}

- Geriatric age.

- $\quad$ Special position- head up position with 2 pillows placed below shoulders and upper back.

- Oral examination- mouth opening 1 finger. MPC grade IV with protruding upper teeth and missing lower teeth.

- $\quad$ Prone position for surgery.

In this anticipated difficult intubation, better option was to go for awake fibreoptic bronchoscopic intubation (FOB) rather than using McCoy blade or video laryngoscope blade. The patient was nebulized with salbutamol and Budecort thrice daily till his day of surgery also chest physiotherapy was done. A written informed anaesthetic consent from the patient for invasive airway management i.e., cricothyroidotomy, tracheostomy and ventilatory support, was taken.

Preoperative fasting guidelines were followed. 30 mins., before the procedure IV access $18 \mathrm{G}$ cannula and IV fluid ringer lactate was started, nebulization with LOX $4 \%$ done, inj. atropine $(0.01 \mathrm{mg} / \mathrm{Kg})$ and promethazine $(0.5 \mathrm{mg} / \mathrm{Kg})$ was given intramuscularly in preoperative room. $\mathrm{O}_{2}$ mask was put on throughout.

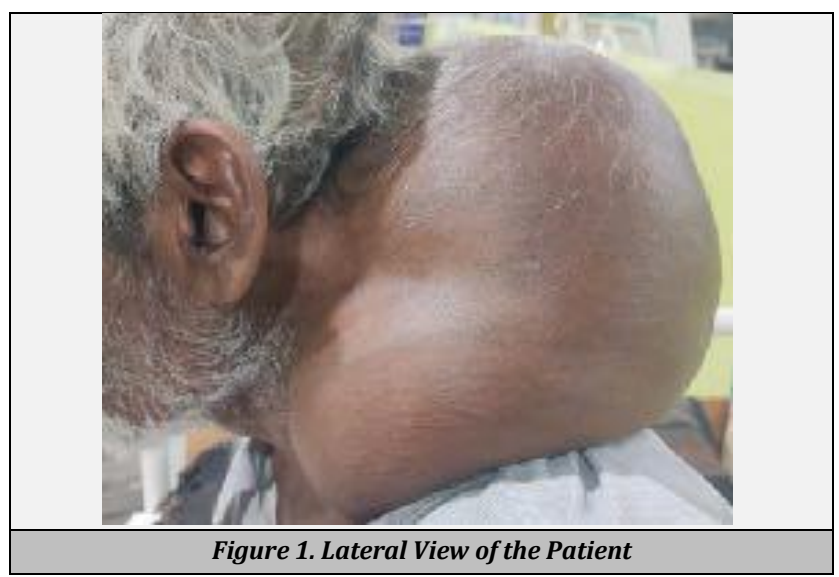

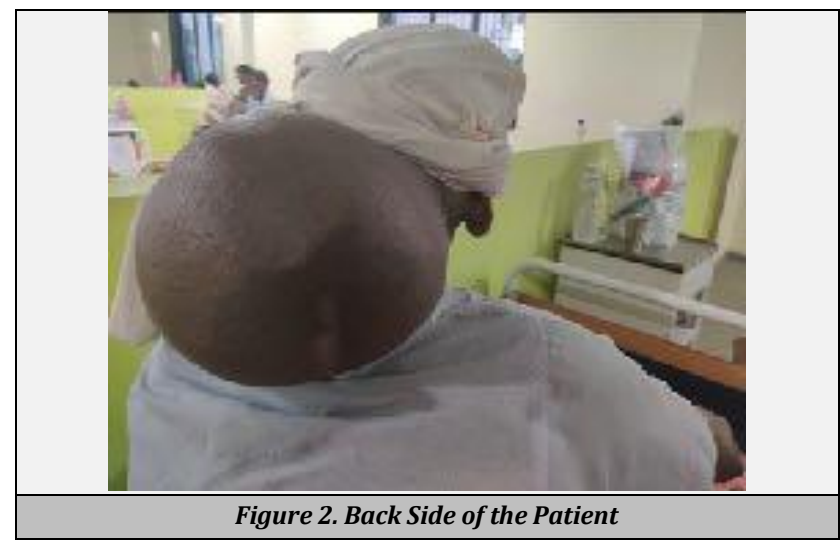
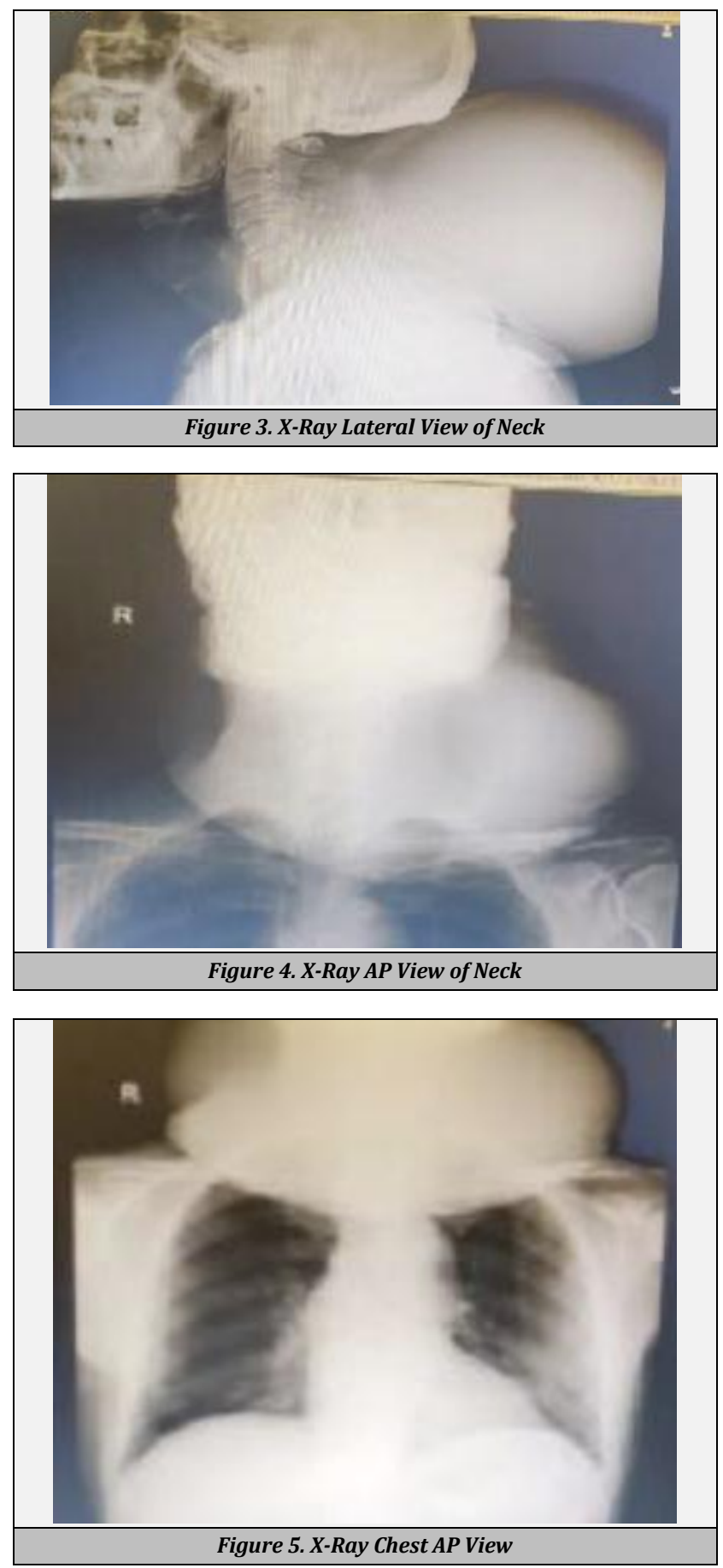

Difficult airway trolley was prepared with emergency drugs like atropine, adrenaline, cardiovascular drugs, bronchodilators, all sized ET tubes for appropriate age and 
smaller, FOB, cricothyroid puncture set, tracheostomy tubes and set, ventilating bougie. The patient was brought to operation theatre and multipara monitors were attached (heart rate, ECG, blood pressure (MAP), respiratory rate, $\mathrm{ETCO}_{2}$ ). The patient was maintaining head-up position, a shoulder ramp was given before FOB. Nerve blocks of airway[recurrent laryngeal nerve(RLN) block included inhalation with lox $4 \%-4 \mathrm{ml}$, superior laryngeal nerve (SLN) block was given using $2 \%-2 \mathrm{ml}$ of lignocaine on either side of neck- greater cornua of hyoid bone, by injecting $2 \mathrm{~mL} 4 \%$ of Lignocaine after aspiration of air trans-tracheal block was performed by inserting a needle into the cricothyroid membrane. Awake fibre optic endoscopy was performed, a 7.0 mm internal diameter (ID) cuffed endotracheal tube (ETT) was then railroaded over the bronchoscope into the trachea and secured. The tube placement was confirmed by fiberoptic viewing of tube tip inside the trachea, inability to vocalize, chest rise and auscultation, end-tidal carbon dioxide. Inj. Midazolam was given during the whole procedure until the placement of the tube. The patient was given inj. fentanyl 1 $\mathrm{mcg} / \mathrm{Kg}$, inducing agent inj. propofol $2 \mathrm{mg} / \mathrm{Kg}$ followed by muscle relaxant inj. vecuronium $0.1 \mathrm{mg} / \mathrm{Kg}$. Prone position was given, all pressure points were taken care with proper padding and bolster placement. Patient was ventilated on volume control mode with TV $8 \mathrm{ml} / \mathrm{Kg}$, RR 16/min, PEEP $5 \mathrm{~cm}$ $\mathrm{H}_{2} \mathrm{O}$, I:E::1:2, maintained on $\mathrm{O}_{2}, \mathrm{~N}_{2} \mathrm{O}$, sevoflurane and vecuronium top-ups. The patient's vitals were unremarkable, analgesia was given with inj. fentanyl $1 \mathrm{mcg} / \mathrm{Kg}$ and later at the near end of surgery inj. paracetamol $20 \mathrm{mg} / \mathrm{Kg}$. No complication was noted intraoperatively. Once the lipoma was removed and closure done, the patient was repositioned supine, reversed. The anticipated plan was to leave the endo tracheal tube in situ keeping in mind difficult airway, prolonged duration of surgery, geriatric age but as the patient could not tolerate the tube and was in severe distress, so extubation was done under strict guidance where difficult airway trolley was arranged along with an emergency tracheostomy set. No post-extubation respiratory compromise was noted.

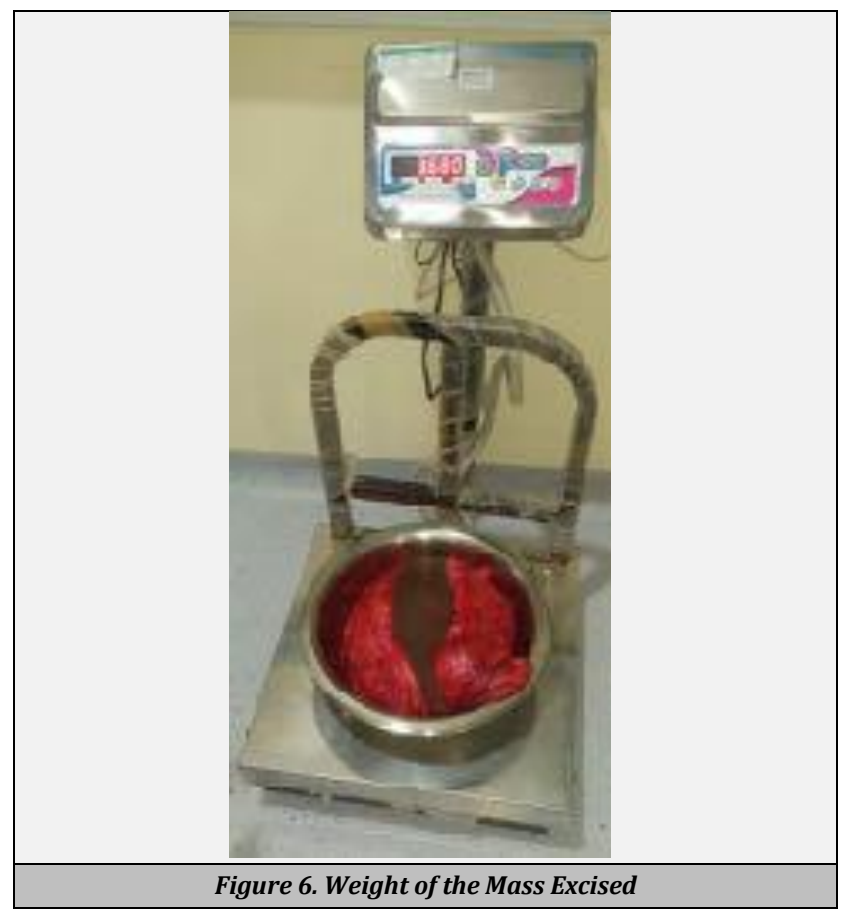

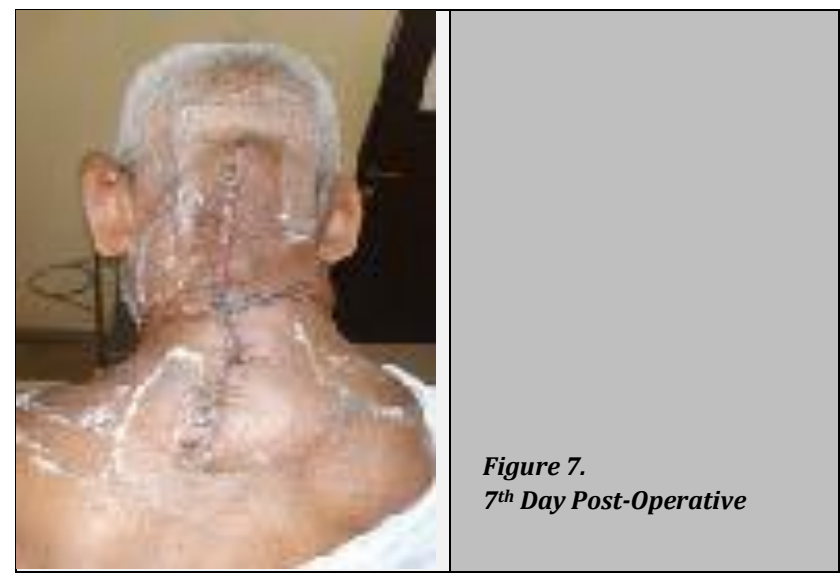

DISCUSSION

Cormack Grade III or IV are significantly associated with difficult intubation.[6] A guideline has been developed for management of difficult tracheal intubation in non-obstetric adults without upper airway obstruction[7] by the Difficult Airway Society. The American Society of Anesthesiologists.[8] executed a closed-claim analysis in surgical patients that $17 \%$ of adverse respiratory events are related to difficult tracheal intubation. The gold standard for an anticipated difficult intubation is awake fibre optic with a flexible bronchoscope intubation. Any large mass around the neck, a direct risk factor for airway management, is a challenge for anaesthesiologists. The hallmark of successful outcome is preoperative assessment of airway, planning of safe intubation procedure, stepwise management to maintain spontaneous ventilation until after successful intubation. Other indirect specific risk factor to difficult intubation need to be recognised is appropriate positioning. ${ }^{[9,10]}$ Securing the airway is best done in supine position. But in our case, the huge mass in the upper back which was itself a risk factor for difficult airway, interfered with the supine position. Besides in addition, the patient had restricted mouth opening of 1 finger. So, we put the patient's head on three head rings and a shoulder ramp before induction on the OT table. Anticipating a difficult airway an awake intubation was planned using a fiber-optic bronchoscope.

\section{CONCLUSIONS}

Proper positioning of the patient is the most important step for induction of anaesthesia as well as securing the airway. This is best done in supine position. In a patient with a huge mass over the back which interferes with a suitable supine position, MPC IV and protruding teeth, fiberoptic bronchoscope for awake intubation is the gold standard.

\section{REFERENCES}

[1] Caplan RA, Benumof JL, Berry FA, et al. Practice guidelines for management of the difficult airway. A report by the American Society of Anesthesiologists Task Force on 
Management of the Difficult Airway. Anesthesiology 1993;78(3):597-602.

[2] Dabbagh A, Mobasseri N, Elyasi H, et al. A rapidly enlarging neck mass: the role of sitting position in fiberoptic bronchoscopy for difficult intubation. Anesth Analg 2008;107(5):1627-9.

[3] Leva E, Pansini L, Fava G, et al. The role of surgeon in case of giant neck mass in the EXIT procedure J Pediatr Surg 2005;40(4):748-50.

[4] Akhlaghi M, Shabanian G, Abedinzadeh M, et al. Special position for the anaesthetic managment of a patient with giant neck and back masses. Ghana Med J 2010;44(1):378.

[5] Sung JK, Kim JE, Jang MS, et al. Endotracheal tube intubation with aid of a laryngeal mask airway, fibreoptic bronchoscope and a tube exchanger in difficult airway patient: a case report. Korean J Anesthesiol 2014;66(3):237-9.
[6] Bouaggad A, Nejmi SE, Bouderka MA, et al. Prediction of difficult tracheal intubation in thyroid surgery. Anesth Analg 2004;99(2):603-6.

[7] Henderson JJ, Popat MT, Latto IP, et al. Difficult airway society guidelines for management of the unanticipated difficult intubation. Anaesthesia 2004;59(7):675-94.

[8] Caplan RA, Posner KL, Ward RJ, et al. Adverse respiratory events in anesthesia: a closed claims analysis. Anesthesiology 1990;72(5):828-33.

[9] Papadonikolakis A, Wiesler ER, Olympio MA, et al. Avoiding catastrophic complications of stroke and death related to shoulder surgery in the sitting position. Arthroscopy 2008;24(4):481-2.

[10] Ralston C, Tatman A. An audit of serious complications during neurosurgery in children using the sitting position. Paediatr Anaesth 2000;10(6):698-9. 